\title{
Porosity Dependence of Elastic Constants in Aluminum Nitride Ceramics
}

\author{
Humberto Naoyuki Yoshimura a*, André Luiz Molisani', Nilson Eiji Narita, \\ Paulo Francisco Cesar ${ }^{\mathrm{b}}$, Hélio Goldenstein ${ }^{\mathrm{b}}$ \\ anstituto de Pesquisas Tecnológicas do Estado de São Paulo, Av. Prof. Almeida Prado, 532, \\ 05508-901 São Paulo - SP, Brazil \\ ${ }^{\mathrm{b}}$ Universidade de São Paulo, Av. Prof. Mello Moraes, 2463, 05508-900, São Paulo - SP, Brazil
}

Received: August 22, 2006; Revised: March 28, 2007

\begin{abstract}
Aluminum nitride is a relatively new engineering ceramic and its mechanical properties have not been extensively studied. In this work, the effects of porosity ( 0 to 38\%) on sonic velocities, Poisson's ratio, and elastic moduli of partially sintered AlN, both pure and with additives, were investigated. The elastic constants, determined by the ultrasonic pulse-echo method, were significantly influenced by the porosity, but not by the different types of additives used ( 2 wt. $(\%)$ of $\mathrm{CaCO}_{3}, \mathrm{CaO}$, and $\mathrm{Y}_{2} \mathrm{O}_{3}$ ). All elastic constants evaluated decreased with increasing porosity, but the rates of decrease were higher for elastic moduli compared do sonic velocities and Poisson's ratio. The results were analyzed in the light of stress concentration and loading bearing area models proposed in the literature.
\end{abstract}

Keywords: aluminum nitride, porous material, elastic behavior, sintering

\section{Introduction}

Aluminum nitride $(\mathrm{AlN})$ ceramic is a potential candidate material for microelectronic substrates because of its high thermal conductivity. Good mechanical properties also make it a potential candidate for use as a structural material for use in heat sinks, ballistic armors, and other applications ${ }^{1,2}$. AlN can be pressureless sintered with the aid of additives, such as $\mathrm{Y}_{2} \mathrm{O}_{3}$ and $\mathrm{CaO}$, which react with the alumina layer on the surface of the AlN particles, forming aluminates that promote densification by liquid-phase sintering ${ }^{3-5}$. Although there are many works related to the sintering behavior and thermal conductivity of AlN ceramics, there are few works concerning to the mechanical behavior of these materials.

The effect of porosity on mechanical properties of ceramic materials has been studied since 1950. Understanding this relationship is important because these materials are mainly produced by powder technology routes and usually have a fraction of involuntary residual porosity, a characteristic which degrades mechanical properties. Moreover, the production of new and reliable porous materials for catalytic supports and filters ${ }^{6}$ depends on the optimization of mechanical properties. Even though many models have been proposed in the literature to predict the effect of porosity on mechanical properties, the reasons for this phenomenon are not completely clear. Therefore, it is important to fit the different models to the experimental data so that their predictability can be verified.

The models can be classified in two groups: models based on geometry (or loading bearing area); and models based on micromechanisms of stress concentration around the pores ${ }^{7,8}$. Some of these models are shown in Table 1. Equations 1 to 8 represent the empirical or semi-analytical models based on the loading area. The interpretation of the fits is based on the geometry of pores or solid particles. Some models based on the "effective" area fraction of loading, namely minimum solid area (MSA) ${ }^{7,14}$, have been proposed with different geometries of pores and solid particles. Equations 9 to 15 (Table 1) represent the analytical models based on stress concentration. Equations 9 to 12 and 15 are proposed for limited concentrations of spherical pores and Equations 13 and 14 for limited concentration of aligned cylindrical pores, with the direction of loading parallel or perpendicular to the direction of the cylindrical pore axis, respectively. Detailed descriptions of the models can be found elsewhere ${ }^{8-13}$. There are other models, such as the numerical model proposed by Chao and Huang, which predicts the elastic moduli of foamed (cellular) materials, taking into account the effect of pore aspect ratio using an Eshelby tensor ${ }^{15}$.

The effect of porosity on elastic constants has been extensively studied for many oxide ceramics ${ }^{8-14,16,17}$ and some covalent ceram$\mathrm{ics}^{8,14,18}$, but there are few works on AIN. In this work, pure and doped AlN ceramics with pore content ranging from 0 to $~ 40 \%$ were prepared by sintering in order to evaluate the effect of porosity on the elastic constants of these materials.

\section{Experimental}

AlN powder (H.C. Stark, Germany, Grade C, $1.06 \mu \mathrm{m}$, 1.63 wt. (\%) O), reagent grade $\mathrm{CaCO}_{3}$ (Anidrol, Brazil, $5.6 \mu \mathrm{m}$ ), calcined $\mathrm{CaO}$ powder $(5.3 \mu \mathrm{m})$, and $\mathrm{Y}_{2} \mathrm{O}_{3}$ powder (H.C. Stark, Grade $\mathrm{C}$, $0.7 \mu \mathrm{m}$ ) were used as raw materials. Pure AlN and mixtures of AlN with 2 wt. (\%) of each additive were ball milled in a plastic jar for 24 hours, using isopropyl alcohol to avoid oxygen contamination. Following the addition of a binder ( $2 \%$ polyethylene glycol), the mixtures were dried in a rotoevaporator. The powders were uniaxially pressed at $10 \mathrm{MPa}$ in a $15 \mathrm{~mm}$ diameter cylindrical die and then CIPed at $150 \mathrm{MPa}$ in order to form disk-shaped green specimens with a thickness of $5 \mathrm{~mm}$. Three specimens were prepared for each test condition. Green specimens were sintered in a tungsten heated furnace (Nems, NM-15, Japan) at 1600,1700 , and $1750{ }^{\circ} \mathrm{C}$ for 7 to 480 minutes under a flowing high purity nitrogen gas. During the heating stage, samples were held at $500{ }^{\circ} \mathrm{C}$ for 0.5 hours to burn out the binder. The heating and cooling rates were 10 and $30^{\circ} \mathrm{C} /$ minutes, respectively.

The green density was determined by geometric method and the density of the sintered bodies by Archimedean's method, using alcohol as immersion liquid. The volume fraction of pores was calculated 
Table 1. Semi-analytical (1 to 8 ) and analytical (9 to 15) equations for elastic constants as a function of volume fraction porosity $\mathrm{P}^{8-13}$. M is an elastic property and E, G, K, and $v$ are Young's, shear, and bulk modulus, and Poisson's ratio, respectively. The subscripts 0 and $g$ indicate the property of the material without pore and green body, respectively. The values of $b, b_{1}, b_{2}$, and $n$ of Equations 1 to 7 are determined by fitting to the experimental results.

\begin{tabular}{|c|c|c|c|}
\hline Author (year) & Reference & Equation & \\
\hline- & $9,10,13$ & $\mathrm{M}=\mathrm{M}_{0}(1-\mathrm{bP})$ & (1) \\
\hline- & 10,13 & $\mathrm{M}=\mathrm{M}_{0}\left(1-\mathrm{b}_{1} \mathrm{P}+\mathrm{b}_{2} \mathrm{P}^{2}\right)$ & (2) \\
\hline Knudsen (1959) & $9,10,13$ & $\mathrm{M}=\mathrm{M}_{0} \exp (-\mathrm{bP})$ & (3) \\
\hline Hasselman (1962) & $9,10,13$ & $\mathrm{E}=\mathrm{E}_{0}(1-\mathrm{P}) /(1+\mathrm{bP})$ & (4) \\
\hline Martin-Haynes (1971) & 9,13 & $\mathrm{E}=\mathrm{E}_{0}\left(1-\mathrm{bP}^{2 / 3}\right)$ & (5) \\
\hline Wang (1984) & 10,13 & $\mathrm{E}=\mathrm{E}_{0} \exp \left(-\mathrm{b}_{1} \mathrm{P}-\mathrm{b}_{2} \mathrm{P}^{2}\right)$ & (6) \\
\hline Phani-Niyogi (1987) & 10 & $\mathrm{E}=\mathrm{E}_{0}(1-\mathrm{bP})^{\mathrm{n}}$ & (7) \\
\hline Lam et al. (1994) & 11 & $\mathrm{E}=\mathrm{E}_{0}\left(1-\mathrm{P} / \mathrm{P}_{\mathrm{g}}\right)$ & (8) \\
\hline Dewey (1947) & 8,13 & $\mathrm{G}=\mathrm{G}_{0}\left[1-15 \mathrm{P}\left(1-\mathrm{v}_{0}\right) /\left(7-5 \mathrm{v}_{0}\right)\right]$ & $(9.1)$ \\
\hline & & $\mathrm{K}=\mathrm{K}_{0}\left[1-3\left(1-\mathrm{v}_{0}\right) \mathrm{P} /\left(2-4 \mathrm{v}_{0}\right)\right.$ & $(9.2)$ \\
\hline Mackenzie (1950) & 8,13 & $\begin{array}{l}\mathrm{G}=\mathrm{G}_{0}\left[1-5 \mathrm{P}\left(3 \mathrm{~K}_{0}+4 \mathrm{G}_{0}\right) /\left(9 \mathrm{~K}_{0}+8 \mathrm{G}_{0}\right)-\mathrm{AP}^{2}\right] \\
\mathrm{K}=\mathrm{K}_{0}\left\{(1-\mathrm{P})^{-1}+3 \mathrm{PK}_{0} /\left[4 \mathrm{G}_{0}(1-\mathrm{P})\right]+\mathrm{BP}^{3}\right\}^{-1}\end{array}$ & $\begin{array}{l}(10.1) \\
(10.2)\end{array}$ \\
\hline Kerner (1952) & 8,13 & $\begin{array}{l}\mathrm{G}=\mathrm{G}_{0}(1-\mathrm{P})\left(7-5 \mathrm{v}_{0}\right) /\left[\mathrm{P}\left(8-10 \mathrm{v}_{0}\right)+7-5 \mathrm{v}_{0}\right] \\
\mathrm{K}=4 \mathrm{~K}_{0} \mathrm{G}_{0}(1-\mathrm{P}) /\left(4 \mathrm{G}_{0}+3 \mathrm{PK}_{0}\right)\end{array}$ & $\begin{array}{l}(11.1) \\
(11.2)\end{array}$ \\
\hline Hashin (1962) & 8,13 & $\begin{array}{l}\mathrm{E}=\mathrm{E}_{0}(1-\mathrm{P}) /\left\{1+\left(1+v_{0}\right)\left(13-15 v_{0}\right) \mathrm{P} /\left[2\left(7-5 v_{0}\right)\right]\right\} \\
\mathrm{G}=\mathrm{G}_{0}(1-\mathrm{P}) /\left[1+2\left(4-5 v_{0}\right) \mathrm{P} /\left(7-5 v_{0}\right)\right] \\
\mathrm{K}=\mathrm{K}_{0}(1-\mathrm{P}) /\left\{1+\left(1+v_{0}\right) \mathrm{P} /\left[2\left(1-2 v_{0}\right)\right]\right\}\end{array}$ & $\begin{array}{l}(12.1) \\
(12.2) \\
(12.3)\end{array}$ \\
\hline Hashin-Rosen (1964) & $8,12,13$ & $\begin{array}{l}\mathrm{E}=\mathrm{E}_{0}(1-\mathrm{P}) \\
\mathrm{G}=\mathrm{G}_{0}(1-\mathrm{P}) /(1+\mathrm{P})\end{array}$ & $\begin{array}{l}(13.1) \\
(13.2)\end{array}$ \\
\hline Hashin-Rosen (1964) & $8,12,13$ & $\mathrm{E}=4 \mathrm{GK}\left\{\mathrm{K}+\mathrm{G}+\mathrm{KGv}_{0}^{2} /\left[\mathrm{E}_{0}(1-\mathrm{P})\right]\right\}$ & $(14.1)$ \\
\hline Budianski (1970) & 8,13 & $\begin{array}{l}\mathrm{G}=\mathrm{G}_{0}\left\{1-4 \mathrm{P}\left(1-\mathrm{v}_{0}\right) /\left[1+2 \mathrm{P}\left(1-2 \mathrm{P}\left(1-2 v_{0}\right)\right]\right\}\right. \\
\left.\mathrm{K}=2 v_{0}\left(\mathrm{~K}_{0}+\mathrm{G}_{0} / 3\right)(1-\mathrm{P}) / \mathrm{P}+2 \mathrm{v}_{0}\right) \\
\mathrm{G}=\mathrm{G}_{0}[1-15 \mathrm{P}(1-\mathrm{v}) /(7-5 v)] \\
\mathrm{K}=\mathrm{K}_{0}[1-3(1-v) \mathrm{P} /(2-4 v)]\end{array}$ & $\begin{array}{l}(14.2) \\
(14.3) \\
(15.1) \\
(15.2)\end{array}$ \\
\hline
\end{tabular}

from the ratio of measured density and theoretical density, which was calculated by rule of mixture assuming the densities of AlN, $\mathrm{CaO}$, and $\mathrm{Y}_{2} \mathrm{O}_{3}$ to be $3.261,3.315$, and 5.015 g. $\mathrm{cm}^{-3}$, respectively ${ }^{19}$. Microstructural analysis was performed in a scanning electron microscope (SEM, Jeol, Japan, JSM 6300) coupled with energy dispersive spectroscopy (EDS, Noram, USA).

Elastic constants were determined by the ultrasonic pulse-echo method (Figure 1) using a $200 \mathrm{MHz}$ ultrasonic pulser-receiver (Panametrics, USA, $5900 \mathrm{PR}), 20 \mathrm{MHz}$ longitudinal and shear transducers with a delay material, and a coupling paste (Panametrics) applied between the sample and transducer ${ }^{13}$. The time of flight of ultrasonic pulse was measured with an oscilloscope (Tektronix, China, TDS 1002) and the thickness of the sample was measured with a digital micrometer (Mitutoyo, Brazil). Sonic velocities were calculated as two times the thickness divided by the time of flight, since in the pulseecho method, only one transducer (longitudinal or shear mode) is used to emit and to capture the back-reflected wave. The Poisson's ratio $(v)$, Young's (E), shear $(\mathrm{G})$, and bulk $(\mathrm{K})$ modulus were calculated applying the measured bulk density $(\rho)$, longitudinal velocity $\left(V_{L}\right)$, and shear velocity $\left(\mathrm{V}_{\mathrm{T}}\right)$ in the following equations $\mathrm{s}^{20}$ :

$$
\begin{aligned}
\nu & =0.5 \cdot \frac{\mathrm{V}_{\mathrm{L}}^{2}-2 \cdot \mathrm{V}_{\mathrm{T}}^{2}}{\mathrm{~V}_{\mathrm{L}}^{2}-\mathrm{V}_{\mathrm{T}}^{2}} \\
\mathrm{E} & =\rho \cdot\left(\frac{3 \cdot \mathrm{V}_{\mathrm{T}}^{2} \cdot \mathrm{V}_{\mathrm{L}}^{2}-4 \cdot \mathrm{V}_{\mathrm{T}}^{4}}{\mathrm{~V}_{\mathrm{L}}^{2}-\mathrm{V}_{\mathrm{T}}^{2}}\right) \\
\mathrm{G} & =\rho \cdot \mathrm{V}_{\mathrm{T}}^{2}
\end{aligned}
$$

$$
\mathrm{K}=\frac{\rho}{3} \cdot\left(3 \cdot \mathrm{V}_{\mathrm{L}}^{2}-4 \cdot \mathrm{V}_{\mathrm{T}}^{2}\right)
$$

\section{Results and Discussion}

The experimental results were plotted without the error bars, since the standard deviations were relatively small. The order of magnitude of the standard deviation can be inferred from the coefficients of variation shown in Table 2 for all measured properties.

The green densities of all samples were $\sim 60 \%$ of the theoretical densities. Porosity decreased with the increase in sintering temperature and time, and the densification of pure AlN sample was slower than the AlN samples with additive $\left(\mathrm{CaO}, \mathrm{CaCO}_{3}\right.$, and $\left.\mathrm{Y}_{2} \mathrm{O}_{3}\right)$, as expected (Figures $2 \mathrm{a}$ and $2 \mathrm{~b}$ ). Samples with additive achieved almost full density at $1750{ }^{\circ} \mathrm{C}$. The elastic constants increased with the increase in sintering temperature and time (Figures $2 \mathrm{c}$ and $2 \mathrm{~d}$ ), indicating an inverse relationship between these constants and porosity.

The microstructural evolution of the samples with increasing sintering temperature and/or time was analyzed by SEM. Typical micrographs of the sintered samples are shown in Figure 3. These micrographs reveal microstructural aspects related to the size and morphology of particles/grains and pores. At the lowest sintering temperature and time $\left(1600{ }^{\circ} \mathrm{C}, 7\right.$ minutes $)$, the samples showed microstructural aspects of the initial stage of the solid state sintering (SSS) process. Most of the AlN particles were linked to adjacent particles, forming a neck between particles and an interconnected network of tortuous porous channels (open porosity, Figure 3a). With the increase in sintering time at $1600{ }^{\circ} \mathrm{C}$, the $\mathrm{AlN}$ particles coarsened and the 

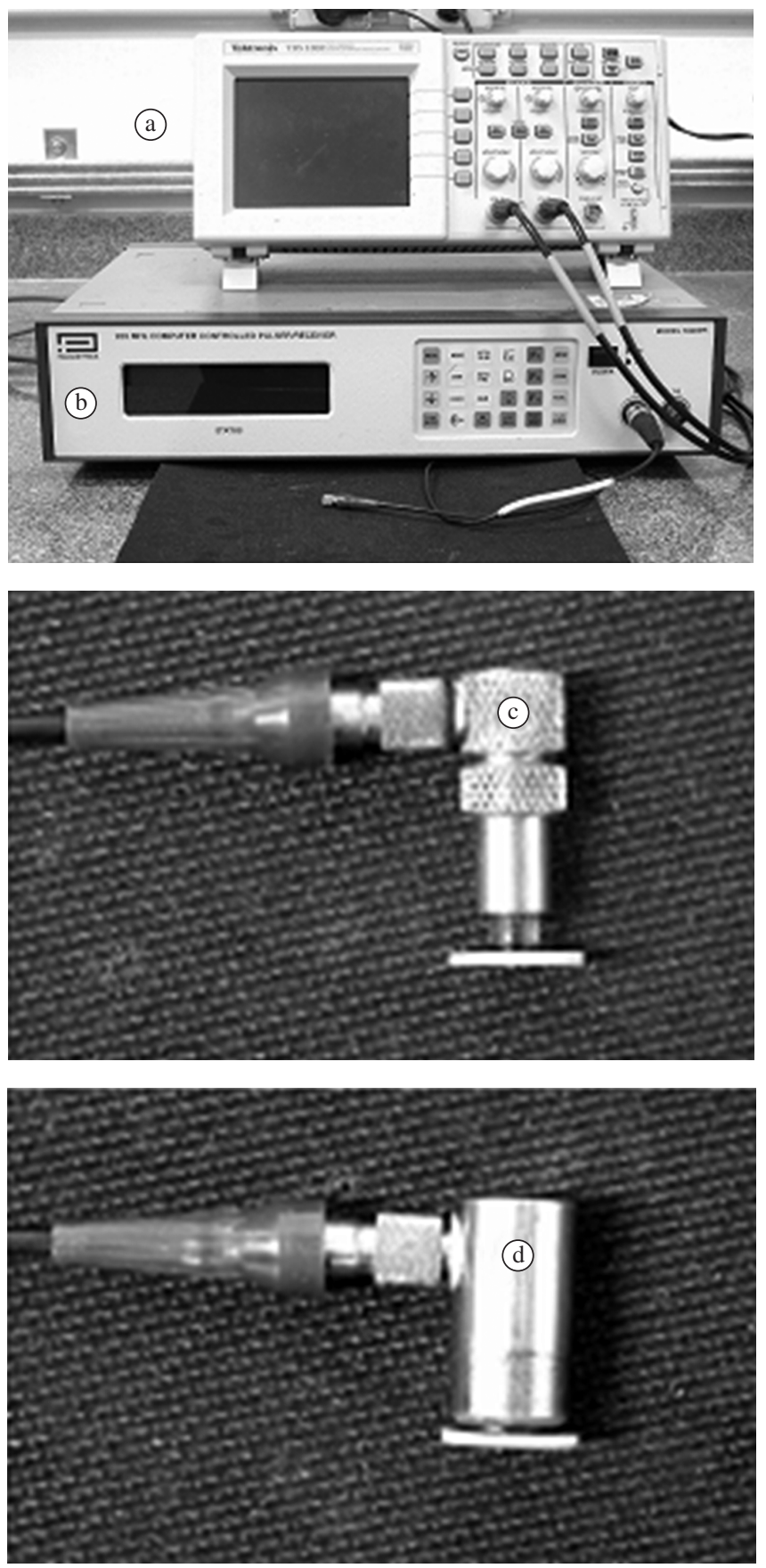

Figure 1. Images of a) oscilloscope, b) ultrasonic pulser-receiver, c) longitudinal wave transducer, and d) shear wave transducer used to measure sonic velocities. In c,d), a disk-shaped specimen in contact with the transducer is also shown.

Table 2. Coefficient of variation of the measured bulk density ( $\rho$ ), volume fraction porosity $(\mathrm{P})$, longitudinal $\left(\mathrm{V}_{\mathrm{L}}\right)$ and shear $\left(\mathrm{V}_{\mathrm{T}}\right)$ velocity, Poisson's ratio (v), Young's (E), shear $(\mathrm{G})$, and bulk $(\mathrm{K})$ modulus.

\begin{tabular}{cccccccc}
\hline$\rho$ & $\mathrm{P}$ & $\mathrm{V}_{\mathrm{L}}$ & $\mathrm{V}_{\mathrm{T}}$ & $\mathrm{V}$ & $\mathrm{E}$ & $\mathrm{G}$ & $\mathrm{K}$ \\
\hline $0.3 \%$ & $1.6 \%$ & $0.6 \%$ & $0.6 \%$ & $2.7 \%$ & $1.2 \%$ & $1.4 \%$ & $1.8 \%$ \\
\hline
\end{tabular}

microstructure became denser, mainly by SSS mechanisms (Figure 3b). At $1700{ }^{\circ} \mathrm{C}$, the liquid phase sintering (LPS) process was activated in the samples with $\mathrm{CaCO}_{3}$ and $\mathrm{CaO}$, leading to the formation of dense agglomerates around the initial additive particles (indicated by letter $\mathrm{A}$

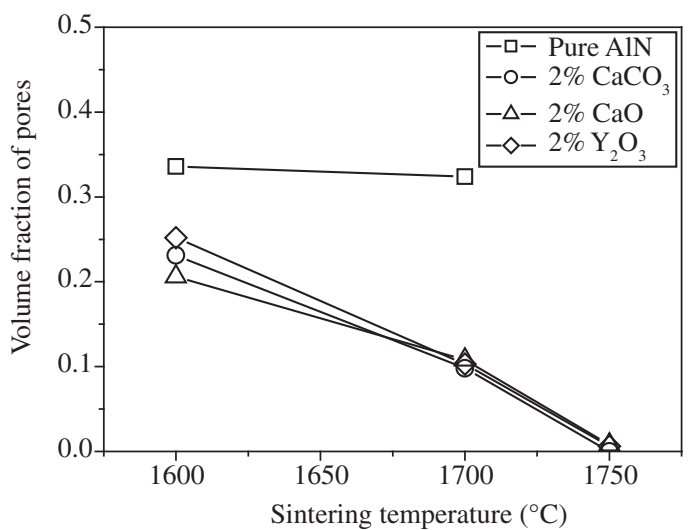

(a)

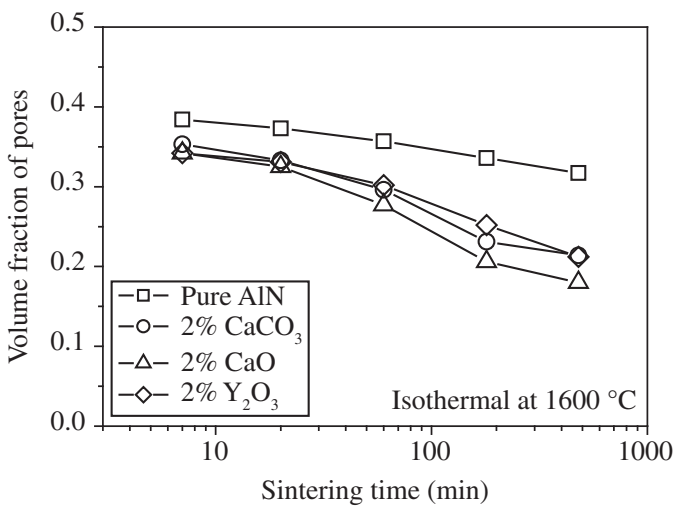

(b)

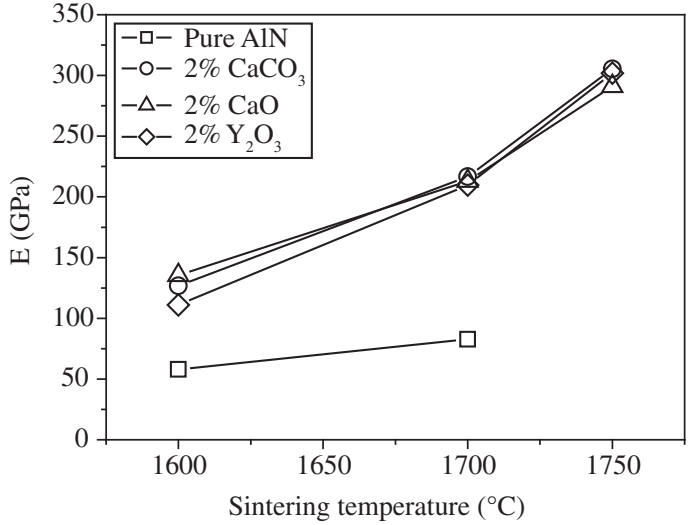

(c)

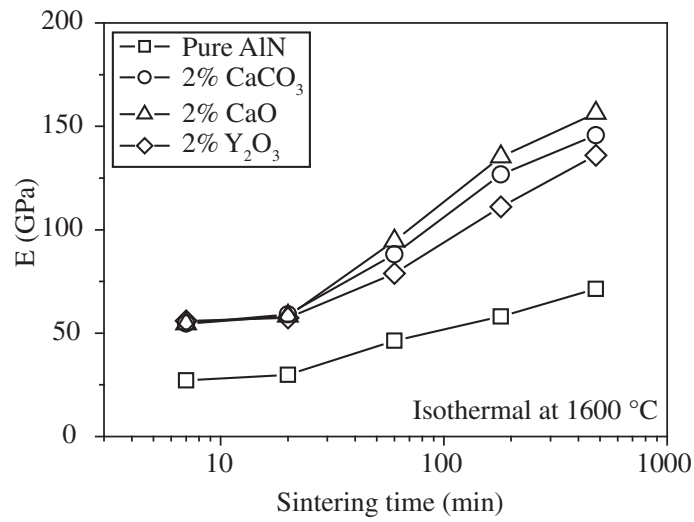

(d)

Figure 2. Porosity as a function of a) sintering temperature (3 hours) and b) sintering time $\left(1600^{\circ} \mathrm{C}\right)$, and Young's modulus as a function of c) sintering temperature (3 hours) and d) sintering time $\left(1600^{\circ} \mathrm{C}\right)$. 

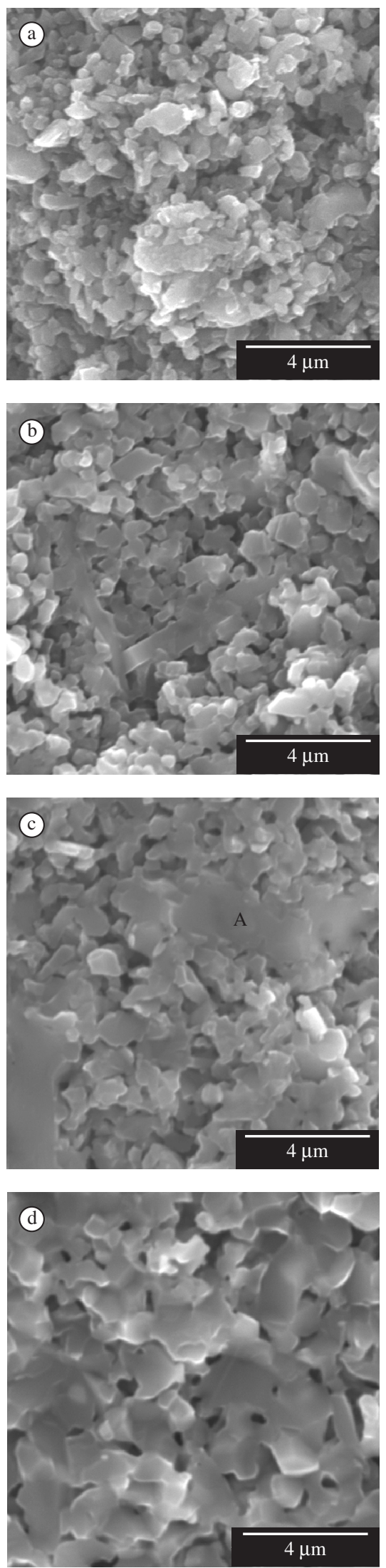

Figure 3. SEM images of: a) $\mathrm{AlN}-2 \% \mathrm{CaO}$ sintered at $1600{ }^{\circ} \mathrm{C}$ for 7 minutes; b) $\mathrm{AlN}-2 \% \mathrm{CaO}$ sintered at $1600{ }^{\circ} \mathrm{C}$ for 8 hours; c) $\mathrm{AlN}-2 \% \mathrm{CaCO}_{3}$ sintered at $1700{ }^{\circ} \mathrm{C}$ for 1 hour; and d) $\mathrm{AlN}-2 \% \mathrm{Y}_{2} \mathrm{O}_{3}$ sintered at $1700{ }^{\circ} \mathrm{C}$ for 8 hours. In c), the letter $\mathrm{A}$ indicates a region with high $\mathrm{Ca}$ content determined by EDS analysis. in Figure 3c). At this temperature, the densification of the sample with added $\mathrm{Y}_{2} \mathrm{O}_{3}$ seemed to be dominated by the SSS process. This result is in accordance with the work of Molisani et al. ${ }^{4}$, which observed that the LPS process started to operate in AlN with $\mathrm{Y}_{2} \mathrm{O}_{3}$ additive only at $1725^{\circ} \mathrm{C}$. After a sintering time of 8 hours at $1700^{\circ} \mathrm{C}$, the samples with additive showed significant densification and grain growth, and some isolated pores with morphology tending to spherical could be observed (Figure 3d). These samples sintered at $1750{ }^{\circ} \mathrm{C}$ (3 hours) presented almost fully dense microstructure and only some residual pores were observed. Pure AlN presented sluggish densification at $1700^{\circ} \mathrm{C}$ by the SSS process. Without the aid of additives, AlN with high density can only be achieved after sintering above $1900{ }^{\circ} \mathrm{C}^{5}$.

Variations in elastic constants as a function of porosity were similar for the samples investigated, since the addition of a small amount ( 2 wt. (\%)) of additives had almost no influence on the elastic constants of AlN. Thus, for each property, the results of all samples were analyzed together.

The results of longitudinal and shear sonic velocities $\left(\mathrm{V}_{\mathrm{L}}\right.$ and $\left.\mathrm{V}_{\mathrm{T}}\right)$ and Poisson's ratio (v) are shown in Figure 4a. Among the first three empirical equations (Equations 1 to 3), the best fits were observed for the second-degree polynomial equation (Equation 2). The values of $\mathrm{V}_{\mathrm{L}}, \mathrm{V}_{\mathrm{T}}$, and $\mathrm{v}$ for zero porosity determined with polynomial fit were $(10284 \pm 164) \mathrm{m} . \mathrm{s}^{-1},(6004 \pm 85) \mathrm{m} . \mathrm{s}^{-1}$, and $(0.239 \pm 0.005)$,

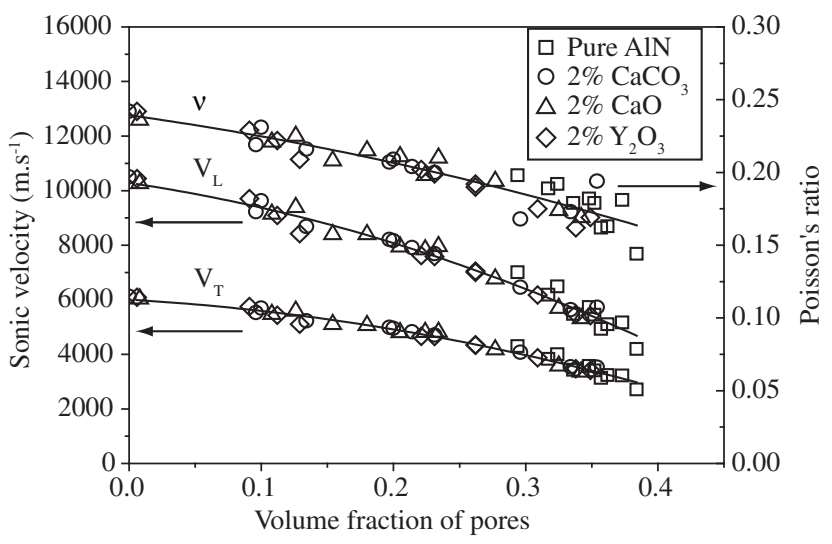

(a)

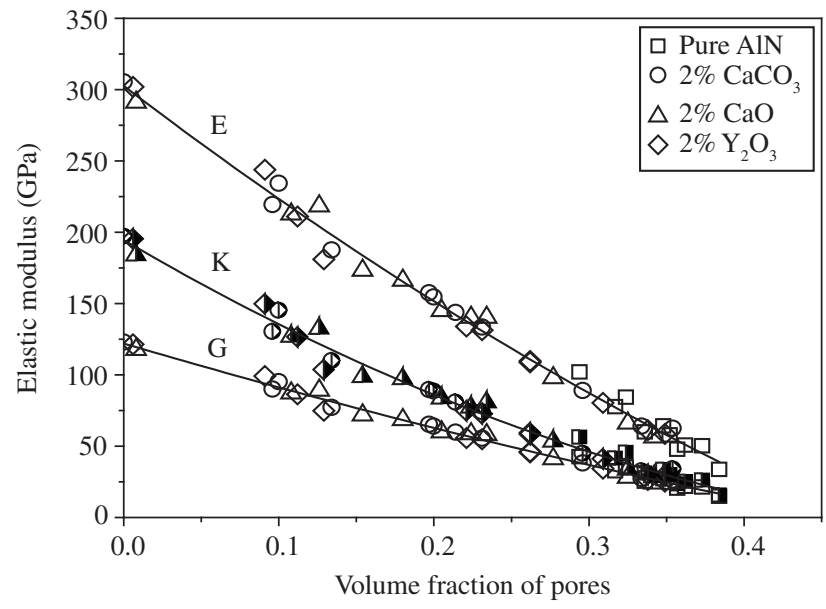

(b)

Figure 4. Results of: a) Longitudinal $\left(\mathrm{V}_{\mathrm{L}}\right)$ and shear $\left(\mathrm{V}_{\mathrm{T}}\right)$ sonic velocities and Poisson's ratio (v); and b) Young's (E), shear (G), and bulk (K) modulus. The curves represent polynomial fit (Equation 2). 
respectively. The values of $\mathrm{V}_{\mathrm{L}}$ and $\mathrm{V}_{\mathrm{T}}$ were close to those measured by Gerlich et al. ${ }^{21}$ for a dense AlN-3 wt. (\%) $\mathrm{Y}_{2} \mathrm{O}_{3}$ (10127 and $6333 \mathrm{~m} \cdot \mathrm{s}^{-1}$, respectively). The reported $v$ value $(0.179)^{21}$, however, was lower than the value obtained in this work $(0.239)$, which was close to that measured by Boch et al. $(0.245)^{22}$.

The results of $\mathrm{E}, \mathrm{G}$, and $\mathrm{K}$ moduli as a function of porosity are shown in Figure 4b. Elastic moduli decreased more rapidly with increasing porosity compared to sonic velocities and v. Empirical and semi-analytical equations (Equations 1 to 8 ) were adjusted to the results and the parameters of these fits are shown in Table 3 for E. The best fits were observed for polynomial and Phani-Niyogi's equations (Equations 2 and 7, respectively). The average values of $\mathrm{E}, \mathrm{G}$, and $\mathrm{K}$ for zero porosity determined with these equations were $(303 \pm 4),(122 \pm 1)$, and $(195 \pm 3) \mathrm{GPa}$, respectively. Boch et al. ${ }^{22}$ observed a linear decrease of the elastic constants with the increase in porosity (up to $20 \%$ ) in AlN without additives prepared by hot pressing. The determined values of $\mathrm{E}$ and $\mathrm{G}$ for zero porosity (314.7 and 126.2 $\mathrm{GPa}$, respectively ${ }^{22}$ ) were close to the values determined in this work (difference less than $4.0 \%$ ). Bruls et al. ${ }^{23}$ measured an $\mathrm{E}$ value of $(312 \pm 4) \mathrm{GPa}$ for hot-pressed AlN. The values of E, G, and $\mathrm{K}$ measured by Gerlich et al. ${ }^{21}$ were 307.6-308.3, 128.3-130.8, and $159.9 \mathrm{GPa}$, respectively. They also reported literature data of $\mathrm{E}$ ranging from 294 to $392 \mathrm{GPa}$ and calculated values of E, G, and K by Voigt averages using single crystal data $(294.5,117.2$, and $201.7 \mathrm{GPa}$, respectively $)^{21}$. Therefore, the measured elastic constants of almost fully dense samples in this work were close to those reported in the literature.

The linear equation (Equation 1) presented good fits (Table 3), but tended to underestimate the elastic moduli for zero porosity. The widely used exponential equation (Equation 3 ) and the equations from Hasselman (Equation 4) and Martin-Haynes (Equation 5) presented poor fits and tended to overestimate the elastic moduli for zero porosity. These equations seem to be applicable only for small ranges of volume fraction of pores. Wang's equation (Equation 6) presented good fits, and the values of the elastic moduli for zero porosity were close to the best fits. The equation from Lam et al. (Equation 8) presented poor fits, mainly for the results of high porosity range (above $30 \%$ ).

The results of elastic constants, normalized with the values determined for zero porosity, were compared to minimum solid area (MSA) models ${ }^{14,24}$ and the rule of mixture (ROM) model in Figure 5. ROM model is a particular form of the linear equation (Equation 1, with $b=1$ ). The Poisson's ratio decreased with the increase in porosity with a rate lower than that predicted by ROM model, while the sonic velocities varied close to the ROM model in the low porosity range and tended to deviate after $\sim 30 \%$ porosity. The elastic moduli initially tended to decrease with the increase in porosity close to two MSA models: spherical pores in cubic stacking and cylindrical pores in cubic stacking aligned transversal to applied stress. SEM analysis revealed the presence of spherical isolated pores in the microstructure of samples with high relative densities (Figure 3d), indicating that the first model is physically more reasonable for consideration. Above $\sim 25 \%$ porosity, the elastic moduli decreased significantly, and in the high porosity range, the values approximated another MSA model: spherical particles in cubic stacking. This analogy is consistent with the result fitted by Phani-Niyogi's equation (Equation 7) that predicted a critical porosity $(\mathrm{Pc}=1 / \mathrm{b}, \mathrm{b}$ in Table 3$)$, at which elastic modulus is zero, close to the Pc for spherical particles arranged in cubic array $(0.476)^{10}$. Since the porosity of the green compacts was 0.40 , the elastic moduli do not become zero at this Pc value. Moreover, Nanjangud et al. ${ }^{25}$ observed in a partially sintered alumina compact that the elastic modulus increased significantly during the initial stage of sintering even when the densification was zero or minimal. Thus, at the porosity of the green compact (0.40), the onset value is expected to be $\sim 6 \%$ of the elastic modulus in a fully dense material ${ }^{25}$.

The gradual transition of the elastic moduli from the model of spherical particles in cubic stacking to the model of spherical pores in cubic stacking with decreasing porosity is consistent with the microstructural evolution during the sintering of a powder compact. In order to evaluate the influence of each of these models during the transition, the average curve of the elastic moduli with porosity,

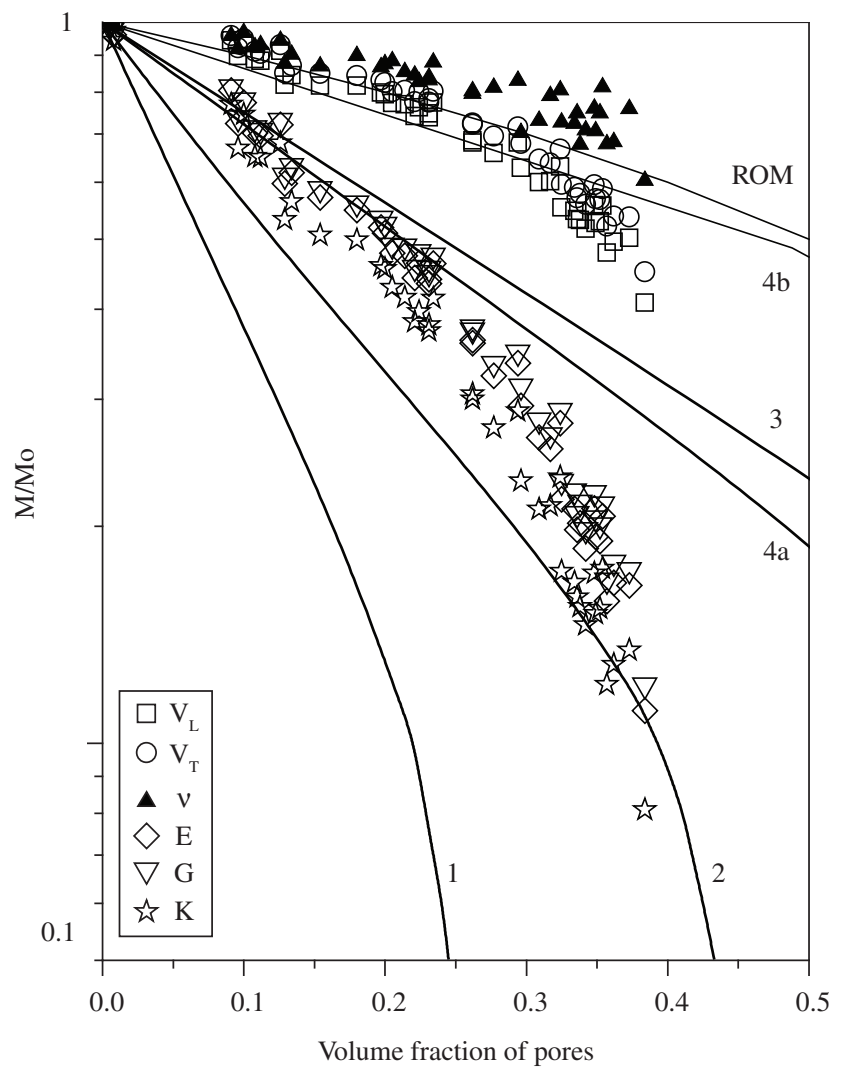

Figure 5. Relative elastic constants versus porosity. The curves indicated by numbers are minimum solid area (MSA) models: 1 - spherical particles in rhombohedral stacking; 2 - spherical particles in cubic stacking; 3 - spherical pores in cubic stacking; $4 \mathrm{a}$ - cylindrical pores in cubic stacking aligned transversal to applied stress; and $4 \mathrm{~b}$ - cylindrical pores in cubic stacking aligned parallel to applied stress. The curve indicated by ROM is rule of mixture.

Table 3. Fitted parameters of Equations 1 to 8 for the results of $\mathrm{E}_{\text {. }} \mathrm{E}_{0}$ is the Young's modulus for zero porosity and OP is b for Equations $1,3,4$, and $5, \mathrm{~b}_{1} / \mathrm{b}_{2}$ for Equations 2 and 6, and b/n for Equation 7.

\begin{tabular}{lcccccccc}
\hline Equation & 1 & 2 & 3 & 4 & 5 & 6 & 7 & 3 \\
\hline $\mathrm{E}_{0}(\mathrm{GPa})$ & $292 \pm 3$ & $303 \pm 4$ & $327 \pm 8$ & $328 \pm 12$ & $331 \pm 5$ & $300 \pm 5$ & $302 \pm 4$ \\
$\mathrm{OP}$ & 2.32 & $2.74 / 1.23$ & 4.28 & 4.56 & 1.63 & $2.08 / 7.09$ & $2.05 / 1.30$ & - \\
$\chi^{2} / \mathrm{R}^{2}$ & $70 / 0.988$ & $52 / 0.991$ & $229 / 0.960$ & $423 / 0.926$ & $104 / 0.982$ & $68 / 0.988$ & $53 / 0.991$ & $202 / 0.964$ \\
\hline
\end{tabular}


obtained by the Phani-Niyogi's equation (Equation 7) fitted to the relative values of the $\mathrm{E}, \mathrm{G}$, and $\mathrm{K}$, was compared to the MSA models. The relative influence of each model was estimated by the rule of mixture. This approach was suggested by Rice ${ }^{7}$, but it seems like it has not been used before. The results (Figure 6) indicated an almost linear relationship between the relative volume fraction of each model that determined the trajectory of elastic moduli with porosity in the range of $\sim 0.04$ and 0.40 . Bellow $\sim 0.04$ porosity, the model of spherical pores in cubic stacking was predominant.

In Figure 7, the relative results of E, G, and K moduli were plotted together with the predicted curves from analytical models based on stress concentration (Equations 9 to 15). In the case of Mackenzie's equation (Equation 10), the second order terms were neglected. This simplification may influence only the range of high porosity ${ }^{8}$. For Budianski model (Equation 15), the values of Poisson's ratio, $v$, were assumed to follow the polynomial fit given in Figure 4a. When the equations predicted only solution for two moduli, the third was calculated from the elastic relationship given by:

$$
E=\frac{9 K G}{3 K+G}
$$

The Hashin-Rosen's model, for bodies with cylindrical pores aligned transversally to the applied stress (Equation 14), showed good fits to the experimental results of $\mathrm{E}$ until $\sim 20 \%$ porosity (Figure $7 \mathrm{a}$ ) and $\mathrm{G}$ until $\sim 35 \%$ porosity (Figure $7 \mathrm{~b}$ ), but overestimated the K modulus (Figure 7c). The equations from Dewey (Equation 9), Mackenzie (Equation 10), and Budianski (Equation 15) showed slightly higher curves than the experimental values of E and G. Dewey's equation (Equation 9.2) showed the best tendency for $\mathrm{K}$ in all porosity ranges, but the predicted values were slightly higher than the experimental results (Figure 7c). The remaining analytical models significantly overestimated the values of elastic moduli. The good predictability of Equation 14 (Hashin-Rosen's model) for E and G, but not for $\mathrm{K}$, was also observed in a high purity alumina ${ }^{13}$. The results also corroborate the observations from Phani ${ }^{12}$ that analytical models based on spherical pores do not fit well to the experimental results of elastic properties and that the models with non-spherical pores, such as cylindrical pores, aligned transversally to the applied stress result in better fits. However, there is no experimental evidence from microstructural analysis (Figure 3 ) to support the assumption of the presence of aligned cylindrical pores in partially sintered ceramic bodies. Moreover, the Poisson's ratios, $v$, calculated from analytical equations (Equations 9 to 15) with the elastic relationship were also

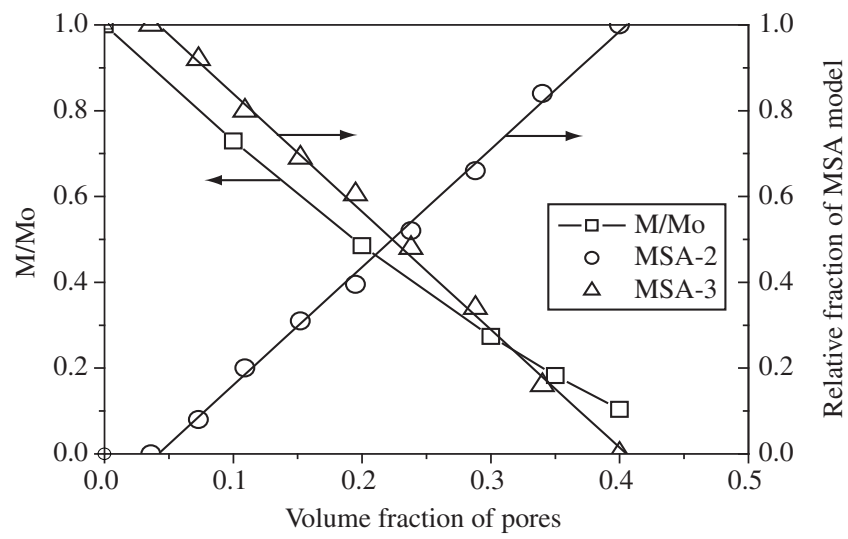

Figure 6. Relative elastic modulus and relative fraction of MSA model versus porosity. MSA-2 is the model of spherical particles in cubic stacking and MSA-3 is the model of spherical pores in cubic stacking.

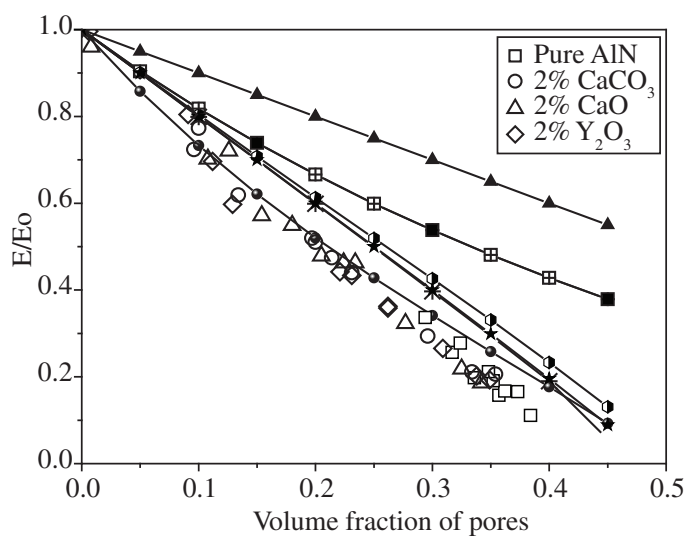

\begin{tabular}{|ll|}
\hline -*-Dewey (Equation 9) & $-\mathbf{-}-$ Hashin-Rosen (Equation 13.1) \\
- - Mackenzie (Equation 10) & $-\bullet-$ Hashin-Rosen (Equation 14.1) \\
一- - Kerner (Equation 11) & $-\star-$ Budiansky (Equation 15) \\
- - Hashin (Equation 12.1) & \\
\hline
\end{tabular}

(a)

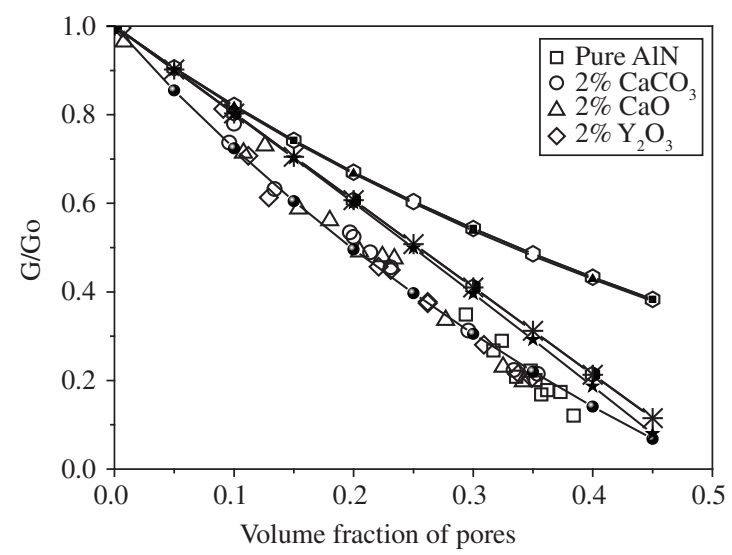

-*-Dewey (Equation 9.1) - - $\quad$ - Hashin-Rosen (Equation 13.2) - - Mackenzie (Equation 10.1) - - - Hashin-Rosen (Equation 14.2) 一田- Kerner (Equation 11.1) - $\quad$ - - Budiansky (Equation 15.1)

- - Hashin (Equation 12.2)

(b)

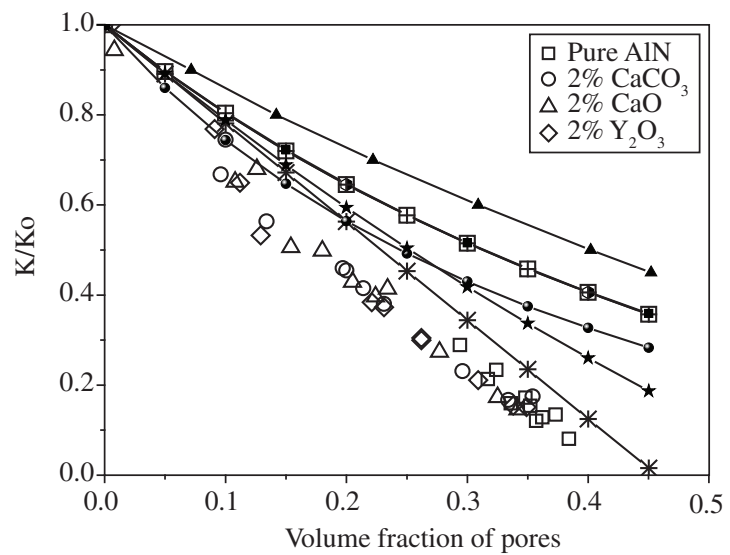

$\begin{array}{ll}\text { - } \text { - Dewey (Equation 9.2) } & \mathbf{-}-\text { - Hashin-Rosen (Equation 13) } \\ \text { - - Mackenzie (Equation 10.2) } & - \text { - Hashin-Rosen (Equation 14.3) } \\ \text { 一- - Kerner (Equation 11.2) } & -\star-\text { Budiansky (Equation 15.2) } \\ \text { - - Hashin (Equation 12.3) } & \end{array}$

(c)

Figure 7. Relative elastic moduli vs. porosity: a) Young's, b) shear, and c) bulk modulus. The curves show analytical models based on stress concentration (Table 1). 
compared to the experimental results, but all models showed overestimated predictions. The inconsistency of the proposed analytical models based on stress concentration to predict the elastic constants (mainly K and $v$ ) reinforces Rice's proposition that shape-stress concentration concepts have little or no fundamental basis to determine elastic properties of porous materials ${ }^{26}$.

\section{Conclusions}

The elastic constants of AlN were significantly influenced by porosity, however they were not affected by the different types of additives used ( 2 wt. (\%) of $\mathrm{CaCO}_{3}, \mathrm{CaO}$, and $\mathrm{Y}_{2} \mathrm{O}_{3}$ ). All elastic constants evaluated $\left(\mathrm{V}_{\mathrm{L}}, \mathrm{V}_{\mathrm{T}}, \mathrm{v}, \mathrm{E}, \mathrm{G}\right.$, and $\left.\mathrm{K}\right)$ decreased with the increase in porosity, but the rates of decrease were higher for elastic moduli compared to sonic velocities and Poisson's ratio. Among the empirical and semi-analytical equations, the best fits in the $\sim 0$ to $38 \%$ porosity range were observed with the second-degree polynomial equation (Equation 2) for all elastic constants, and also with the Phani-Niyogi's equation (Equation 7) for elastic moduli.

The effect of porosity on Poisson's ratio was lower than that predicted by the rule of mixture. Sonic velocities decreased with the increase in porosity following the rule of mixture up to $30 \%$ porosity. The analysis of elastic modulus results by minimum solid area models indicated that, up to $4 \%$ porosity, the model for spherical pores in cubic stacking was predominant and, above this porosity level, an almost linear transition occurred to the model of spherical particles in cubic stacking. The analytical model with the best fit to the results of $\mathrm{E}$ and $\mathrm{G}$ moduli (up to 20 and $30 \%$ porosity, respectively) was the Hashin-Rosen's model for cylindrical pores aligned transversally to the applied stress.

\section{Acknowledgments}

The authors acknowledge Brazilian agencies, FAPESP and CNPq, for their financial support of the present research.

\section{References}

1. Holmquist TJ, Templeton DW, Bishnoi KD. Constitutive modeling of aluminum nitride for large strain, high-strain rate, and high-pressure applications. Int J Impact Eng. 2001; 25(3):211-231.

2. Tangen I-L, Yu Y, Grande T, Høier R, Einarsrud MA. Phase relations and microstructural development of aluminum nitride-aluminum nitride polytypoid composites in the aluminum nitride-alumina-yttria system. J Am Ceram Soc. 2004; 87(9):1734-1740.

3. Qiao L, Zhou H, Xue H, Wang S. Effects of $\mathrm{Y}_{2} \mathrm{O}_{3}$ on low temperature sintering and thermal conductivity of AlN ceramics. J Eur Ceram Soc. 2003; 23(1):61-67.

4. Molisani AL, Yoshimura HN, Goldenstein $\mathrm{H}$. Efeito do teor de $\mathrm{Y}_{2} \mathrm{O}_{3}$ na sinterização do nitreto de alumínio. Cerâmica. 2006; 52(322):151-160.

5. Molisani AL, Yoshimura $\mathrm{HN}$, Goldenstein $\mathrm{H}$, Watari K. Effects of $\mathrm{CaCO}_{3}$ content on the densification of aluminum nitride. J Eur Ceram Soc. 2006; 26(15):3431-3440.

6. Kim YW, Jin YJ, Chun YS, Song IH, Kim HD. A simple pressing route to closed-cell microcellular ceramics. Scripta Mater. 2005; 53(8):921-925
7. Rice RW. Evaluation and extension of physical property-porosity models based on minimum solid area. J Mater Sci. 1996; 31(1):102-118.

8. Rice RW. Microstructure dependence of mechanical behavior of ceramics. In: MacCrone RK, editor. Properties and microstructures. New York: Academic Press; 1977. p. 199-381. (Treatise on Materials Science and Technology, vol 11).

9. Dean EA, Lopez JA. Empirical dependence of elastic moduli on porosity for ceramic materials. J Am Ceram Soc. 1983; 66(5):366-370.

10. Phani KK, Niyogi SK. Young's modulus of porous brittle solids. J Mater Sci. 1987; 22(12):257-263.

11. Lam DCC, Lange FF, Evans AG. Mechanical properties of partially dense alumina produced from powder compacts. J Am Ceram Soc. 1994; 77(8):2113-2117.

12. Phani KK. Porosity-dependence of elastic properties and ultrasonic velocity in polycrystalline alumina-a model based on cylindrical pores. J Mater Sci. 1996; 31(1):262-266.

13. Yoshimura HN, Molisani AL, Siqueira GR, Camargo AC, Narita NE, Cesar PF et al. Efeito da porosidade nas propriedades mecânicas de uma alumina de elevada pureza. Cerâmica. 2005; 51(319):239-251.

14. Rice RW. Comparison of physical property-porosity behaviour with minimum solid area models. J Mater Sci. 1996; 31(6):1509-1528.

15. Chao LP, Huang, JH. Prediction of elastic moduli of porous materials with equivalent inclusion method. $J$ Reinforc Plast Compos. 1999;18(7):592-605.

16. Ostrowski T, Rödel J. Evolution of mechanical properties of porous alumina during free sintering and hot pressing. J Am Ceram Soc. 1999; 82(11):3080-3086.

17. Deng AY, Zhou Y, Inagaki Y, Ando M, Ohji T. Role of $\mathrm{Zr}(\mathrm{OH})_{4}$ hard agglomerates in fabricating porous $\mathrm{ZrO}_{2}$ ceramics and the reinforcing mechanisms. Acta Mater. 2003; 51(3):731-739.

18. Reyanud C, Thevenot F. Porosity dependence of mechanical properties of porous sintered $\mathrm{SiC}$ : verification of the minimum solid area model. $J$ Mater Sci Lett. 2000; 19:871-874.

19. Molisani AL. Sinterização de nitreto de alumínio com compostos contendo cálcio. [Unpublished M.Sc thesis]. São Paulo: University of São Paulo; 2004.

20. American Society for Testing and Materials. ASTM E 494 - Standard practice for measuring ultrasonic velocity in materials. Philadelphia: American Society for Testing and Materials; 2002.

21. Gerlich D, Dole SL, Slack GA. Elastic properties of aluminum nitride. J Phys Chem Solids. 1986; 47(5):437-441.

22. Boch P, Glandus J, Jarrige J, Lecompte JP, Mesmain J. Sintering, oxidation and mechanical properties of hot pressed aluminium nitride. Ceram Inter. 1982; 8(1):34-40.

23. Bruls RJ, Hintzen HT, De With G, Metselaar R. The temperature dependence of the Young's modulus of $\mathrm{MgSiN}_{2}, \mathrm{AlN}$ and $\mathrm{Si}_{3} \mathrm{~N}_{4}$. J Eur Ceram Soc. 2001; 21(3):263-268.

24. Knudsen FP. Dependence of mechanical strength of brittle polycrystalline specimens on porosity and grain size. J Am Ceram Soc. 1959; 42(8):376-387.

25. Nanjangud SC, Brezny R, Green DJ. Strength and Young's modulus behavior of a partially sintered porous alumina. J Am Ceram Soc. 1995; 78(11):266-268.

26. Rice RW. Comparison of stress concentration versus minimum solid area based mechanical property-porosity relations. J Mater Sci. 1993; 28(8):2187-2190. 